\title{
NiCARAGUA: DESDEMOCRATIZACIÓN Y CAUDILLISMO
}

\author{
Nicaragua: De-democratization and Caudillism
}

\section{SALVADOR MARTÍ I PUIG*}

Universidad de Girona

\begin{abstract}
RESUMEN
El texto analiza el proceso de desdemocratización de Nicaragua a partir de tres fenómenos: la instauración progresiva de elecciones autoritarias a partir de 2007, la reforma de la Constitución de 2014, con la que el sistema político vuelve a convertirse en hiperpresidencial de iure, y la capacidad de Ortega de establecer una amplia política de alianzas mediante una lógica caudillista con pretensiones hegemónicas. En las conclusiones se pretende calificar el tipo de régimen que se ha consolidado en Nicaragua y cómo la deriva autoritaria ha intentado despojar cualquier tipo de incertidumbre respecto de las elecciones de 2016.
\end{abstract}

Palabras clave: Nicaragua, Daniel Ortega, FSLN, elecciones autoritarias, desdemocratización.

\begin{abstract}
This article analyses Nicaragua's process of de-democratization focusing on three events: the gradual emergence of authoritarian elections after 2007; the constitutional reform of 2014, by means of which the political system became in legal terms once again hyper-presidential; and Ortega's capacity to establish a broad policy of alliances through a strongman logic with hegemonic intentions. The conclusions aim to identify the type of regime that has become consolidated in Nicaragua and how its authoritarian tendencies have sought to remove any uncertainty regarding the elections of 2016.
\end{abstract}

Key words: Nicaragua, Daniel Ortega, FSLN, authoritarian elections, de-democratization.

* Agradezco los comentarios realizados por los amigos y colegas Ilka Tremino, Midred Largaespada, Gabriel Álvarez, David Close, Miguel González, Andrés Pérez Baltodano, Joan Vintró, y a dos revisores externos. 


\section{ARGUMENTO}

Para muchas personas que se solidarizaron durante los años ochenta con la causa sandinista, les es muy difícil reconocer al "nuevo sandinismo". El discurso de la Primera Dama, Rosario Murillo, proclamando que Nicaragua es "cristiana, socialista y solidaria" y que está "unida en fe, familia y comunidad", se parece muy poco a las proclamas revolucionarias y antiimperialistas de los nueve Comandantes de la Revolución. Solo se necesita abrir la página web de cualquier departamento del gobierno de Nicaragua para ver que las cosas han cambiado mucho. Los colores del FSLN (rojo y negro) se han sustituido por el color "rosa chicha" y el liderazgo coral de los nueve comandantes se ha restringido al de Daniel Ortega y su esposa.

A partir de esta constatación, el texto que sigue pretende analizar cuál es el tipo de régimen que se ha instaurado en Nicaragua desde la llegada de Daniel Ortega en 2007. Esta pretensión no es sencilla, ya que la vuelta del FSLN no ha supuesto ni la vuelta a un régimen revolucionario con tintes socialistas ni tampoco la continuidad del sistema liberal democrático que se instauró después de las elecciones de 1990. Con este fin se abordan los temas de la desdemocratización del juego electoral, la reforma constitucional de 2014 y los equilibrios del poder que sostienen el régimen.

\section{LA DERIVA AUTORITARIA DEL JUEGO ELECTORAL, 1990-1996}

Como señala McConnell (2009), el desarrollo del sistema electoral nicaragüense desde las primeras elecciones competitivas en 1990 no ha mostrado un progreso lineal hacia la profundización democrática. Desde 1990 hasta el 2000 se llevó a cabo un avance sustancial hacia la consolidación democrática en el ámbito electoral, pero a partir de entonces ha habido una progresiva regresión que ha puesto de manifiesto el incremento sostenido de la influencia partidista en las estructuras y los procesos administrativos hasta el punto de que, a partir de las elecciones municipales de 2008, ha desaparecido la competencia partidaria. Con todo, si bien los comicios de 2008 podían calificarse de unas típicas elecciones "autoritarias y contestadas" (Schedler, 2013), a partir de 2011 las elecciones organizadas en Nicaragua son propias ya de un régimen hegemónico consolidado. Con el objetivo de analizar este proceso de progresiva depauperación de la actividad electoral en Nicaragua dividiremos este epígrafe en dos partes. En la primera haremos un rápido repaso por la historia electoral nicaragüense desde 1990 hasta hoy, mientras que en la segunda desarrollaremos una sistematización de las estrategias que se han ido utilizando por parte de los incumbents para desdemocratizar los comicios.

Las elecciones de 1990, que se saldaron con la derrota del FSLN, pusieron fin al proceso revolucionario y también a la guerra de la Contra. ${ }^{1}$ Tal como expone McConnell (2011), las

1 También es preciso exponer, sin embargo, que el proceso electoral de 1900 se desarrolló en el marco de una nación agredida militarmente por un ejército irregular que se movilizaba en las zonas campesinas del interior, de múltiples declaraciones de los altos funcionarios de la administración norteamericana sobre el futuro de 
elecciones de 1990 pueden considerarse las "elecciones fundacionales" de la democracia nicaragüense, ya que fueron las primeras en la historia del país que lograron atraer la participación de todos los partidos políticos y establecer una lógica competitiva, con la presencia de cientos de observadores internacionales. Para ello se llevó a cabo una reforma de la Ley Electoral existente en 1989 en donde se pudieron registrar todos los partidos y alianzas sin obstáculos, creándose una coalición de 14 partidos llamada UNO, que compitió, junto con otras formaciones, contra el FSLN. La institución encargada de la organización de los comicios fue el Consejo Supremo Electoral (CSE), conformado por cinco magistrados, cuatro de ellos afines al FSLN y sus aliados, pero bajo la vigilancia de la Organización de las Naciones Unidas para la Verificación Electoral en Nicaragua (ONUVEN) y el monitoreo de diversos organismos de la comunidad internacional.

Contra la mayoría de los pronósticos el FSLN perdió las elecciones. Como resultado, la presidencia correspondió a Violeta Barrios de Chamorro y 51 de los 90 escaños de la Asamblea Nacional ${ }^{2}$ a formaciones no sandinistas, mientras que el FSLN ganó 39 escaños. Con ello los comicios tuvieron tres consecuencias inmediatas: el fortalecimiento del pluralismo en el país; el encauzamiento de la actividad política en el marco de la Constitución de 1987, descartando la vía armada; y la modificación de la correlación de fuerzas en el plano político, social y económico. Así, el proceso electoral nicaragüense ofreció un claro ejemplo de pacto institucional a partir del cual los diferentes actores establecieron acuerdos, reglas de juego y garantías suficientes como para concurrir en unos comicios y asumir la incertidumbre que estos comportan (Przeworski, 1986).

Los acontecimientos políticos durante el lustro siguiente fueron de tal intensidad que en las elecciones de 1996 el FSLN había sufrido una escisión y la coalición de la UNO desapareció (Martí i Puig, 2013b). En ese contexto se reformó la Constitución en 1995 con el objetivo de reducir los poderes de la Presidencia y también modificar el sistema electoral. Respecto del sistema electoral, se cambió la forma de elegir al Presidente, que se pasó de una elección por mayoría simple a otra en la que si ningún candidato podía obtener el $45 \%$ de los votos, era necesario celebrar una segunda vuelta; se prohibió que los familiares del Presidente fueran candidatos al Poder Ejecutivo y se acortó su mandato de seis a cinco años. ${ }^{3} \mathrm{~A}$ la vez, también hubo reformas en cuanto a la composición de la administración electoral, pasando de un modelo en el que los miembros se elegían entre una base de ciudadanos capacitados sin vinculación partidaria a otro "partidarizado", en el que las autoridades electorales serían elegidas a partir de listas propuestas por fuerzas políticas, introduciendo el peligro de politizar el aparato electoral. Esta decisión supuso la renuncia del entonces presidente del CSE, responsable de las elecciones de 1990, y la necesidad de crear en un año una nueva administración para llevar a cabo las elecciones de 1996.

Nicaragua en caso de ganar los sandinistas, y de una crisis económica acentuada por el bloqueo financiero y comercial de los Estados Unidos. En este sentido véase: Martí i Puig (2013b).

2 A los 90 se sumaron dos escaños de los candidatos presidenciales que quedaron en segunda y tercera posición.

3 La reforma constitucional de 1995 es descrita detalladamente en Close (1999). 
Con esta nueva normativa se realizaron las elecciones del 20 de octubre de 1996, otra vez con observación internacional (con misiones de la OEA, la Unión Europea, asociaciones internacionales de Solidaridad y del Centro Carter) y nacional (con una asociación llamada Ética y Transparencia). En estas elecciones se eligieron simultáneamente los cargos para la Presidencia de la República, la Asamblea Nacional, las alcaldías, los Concejos Locales y el Parlamento Centroamericano, y participaron 23 candidaturas para la presidencia y hubo una amplia oferta partidaria para la Asamblea Nacional. Esta sobreoferta partidaria fue fruto del fácil acceso a fondos disponibles antes de las elecciones y a su automático reconocimiento por parte del CSE. Pero esta realidad supuso una compleja logística electoral. A pesar de la amplia oferta partidaria, la elección se polarizó entre el FSLN y el PLC, un partido liberal y antisandinista liderado por el entonces alcalde de Managua, Arnoldo Alemán. Con todo, los comicios fueron pacíficos y ordenados; si bien hubo problemas de logística en el conteo, sobre todo en algunas regiones del interior. Fruto de este desorden las autoridades tardaron 19 días en dar a conocer los resultados "provisionales", si bien no puede decirse que hubiera fraude, pues los dos instrumentos necesarios para llevarlo a cabo (el censo electoral y el conteo final) no estuvieron bajo responsabilidad de una sola fuerza política (McConell, 2009). De todas formas sí es posible afirmar que los incidentes y la partidarización de la gestión electoral mermó la credibilidad del proceso, sobre todo de los perdedores, quienes impugnaron mesas electorales y pidieron un reconteo que nunca se dio. Al final, los resultados reflejaron la polarización política entre antisandinistas y el FSLN, si bien la victoria de Arnoldo Alemán fue abultada, con el 51\% del sufragio respecto del 37,7\% que obtuvo Ortega. En el ámbito legislativo los resultados fueron muy semejantes a las presidenciales, y de los 90 escaños 42 fueron para los liberales y 36 para el FSLN. ${ }^{4}$ A nivel municipal los liberales ganaron 92 alcaldías y los sandinistas 51 .

La administración de Arnoldo Alemán (1997-2001) fue polémica, pero el evento político más controvertido y relevante del mandato fue la firma en enero de 2000 de un pacto llamado oficialmente "acuerdo de gobernabilidad" (y que popularmente se conoció como "El Pacto") entre Alemán y Ortega con el que partidarizaron el Poder Judicial, la administración electoral (el CSE) y las demás agencias de control. ${ }^{5}$ Con él, los dos líderes políticos reformaron otra vez la Ley Electoral ${ }^{6}$ para reducir de forma drástica el acceso de los partidos a las elecciones, transformar el sistema electoral para elegir a los diputados de la Asamblea Nacional (con dos tipos de circunscripción ${ }^{7}$ ) y para escoger al Presidente de la República bajando el umbral del 45\% para ser elegido en primera

4 Los siguientes se repartieron de la siguiente forma: 4 para Camino Cristiano, 3 para el Partido Conservador, 2 para el Proyecto Nacional, 3 para el MRS, 1 para UNO-96 y 1 para PLI.

5 Para una descripción detallada del pacto de 2000 y la reforma de la Ley Electoral ver Dye, Spence y Vickers (2000).

6 La reforma de 2000 de la Ley Electoral fue publicada en La Gaceta: Diario Oficial. 24 de enero 2000, pp. 361-388. El texto está disponible en la página web del CSE, http:/ / www.cse.gob.ni/index.php?s=8\&\&ley=1\&\&p=1. Este pacto está comentado en el artículo Martí i Puig (2008).

7 Una es la circunscripción nacional de 20 escaños, y otra es de carácter departamental, variando su tamaño según la población (Managua tiene 19 y Río San Juan 1). 
vuelta al $40 \%$, o a $35 \%$ del sufragio si la diferencia entre los dos candidatos mejor situados es superior al $5 \%$.

La primera prueba del funcionamiento de este "pacto" llegó con las elecciones municipales de 2000, que se celebraron de manera separada de los comicios nacionales por primera vez, y en la que se llevaron a cabo algunas decisiones del CSE realmente controvertidas, como la de cambiar la forma del distrito de la ciudad de Managua para excluir de la competición al aspirante más popular, un independiente de origen conservador, realizando un caso ejemplar de gerrymandering. El resultado de estos comicios dieron la mayoría de las alcaldías a los liberales (94), seguido por el FSLN (52) y el Partido Conservador (5).

Posteriormente, las elecciones presidenciales y legislativas de 2001 volvieron a dar la victoria al liberalismo con Enrique Bolaños como candidato a la presidencia (y que obtuvo 56,3\% del sufragio) y la mayoría en la Asamblea Nacional, con 53 escaños. Si bien Bolaños fue el candidato que propuso Alemán, quien no podía presentarse por el hecho de que la Constitución reformada no permitía la reelección inmediata (art. 147), pronto los dos líderes liberales se pelearon. Esta pelea supuso la división del liberalismo en dos bloques, y la denuncia y encarcelamiento por corrupción de Alemán. Esta división del liberalismo fue lo que facilitó, posteriormente, la llegada de Ortega al poder en las siguientes elecciones presidenciales.

Los comicios de 2006 pueden calificarse de "elecciones críticas" (Martí i Puig, 2008), ya que estuvieron marcadas por un cambio en el sistema de partidos, que pasó de enfrentar a sandinistas y antisandinistas, a una contienda a cuatro bandas, debido a la concurrencia de formaciones escindidas del sandinismo y el liberalismo contrarias a El Pacto. En estas elecciones, a raíz del nuevo sistema electoral que bajaba el umbral para obtener la Presidencia de la República, Daniel Ortega se alzó con la victoria con el 38,07\% de los sufragios, ya que aventajaba con más de $5 \%$ de votos al segundo candidato. Con ello, el FSLN obtuvo la presidencia y una mayoría simple de escaños en la Asamblea Nacional y en el Parlamento Centroamericano. Esta victoria se explica por tres cuestiones, dos de ellas ligadas a El Pacto: La Ley Electoral de 2000 que redujo el umbral requerido para obtener la máxima magistratura; el surgimiento de nuevas fuerzas políticas producto del rechazo al El Pacto, que evitó el tradicional duelo "sandinismo vs. antisandinismo"; y la campaña que hizo el FSLN, basada en un discurso desideologizado que apelaba a la paz y la reconciliación, y un acercamiento a los sectores más conservadores de la sociedad mediante la modificación de posturas morales como el caso del aborto terapéutico.

Con la llegada del FSLN al poder los sandinistas encontraron una administración judicial y electoral partidarizada a su favor y una oposición atomizada y, con ello, empezaron a trabajar en el proyecto de neutralizar la naturaleza competitiva del sistema electoral, si bien no tenían la mayoría en la Asamblea Nacional.

El primer evento de esta deriva fueron los comicios municipales de 2008. Para ello, antes de su celebración el CSE dejó sin personería jurídica al Partido Conservador y a la escisión sandinista contraria a El Pacto, el Movimiento de Renovación Sandinista (MRS) aludiendo el incumplimiento de la Ley Electoral; negó y dificultó la acreditación de las comisiones de observación de la OEA y del Centro Carter; controló partidariamente 
los padrones electorales y en el proceso de cedulación y, finalmente, prohibió realizar encuestas a pie de urna (McConell, 2009). Además, después de la celebración de los comicios también se ignoraron las múltiples denuncias de fraude reportadas durante el día de las elecciones, sobre todo respecto de las alcaldías de Managua y León (Martí i Puig, 2013a).

En respuesta a la opacidad institucional la oposición convocó protestas masivas en las calles de las dos mayores ciudades (Managua y León) denunciando el fraude, y hubo duros enfrentamientos entre estos y grupos de choque progubernamentales. Sin embargo, más allá de las denuncias de amplios sectores sociales y determinados medios de comunicación, el CSE certificó una amplia victoria del FSLN (con 105 alcaldías) y no aceptó ninguna de las denuncias, hecho que supuso un duro golpe a la credibilidad de las elecciones en Nicaragua y de la institución electoral en particular. ¿Con ello se puede certificar que hubo fraude en los comicios? Es muy difícil responder esta pregunta debido a problemas estructurales de información en Nicaragua, pues la gran mayoría de las prácticas de manipulación electoral son ilegales y se llevan a escondidas. Como expone Schedler (2013), los problemas de observación y evaluación electoral son endógenos a los regímenes autoritarios, pues estos son grandes expertos en generar ambigüedad e inconsistencia calculada.

Lo que sí puede afirmarse es que después de las elecciones de 2008 ya no se han celebrado más sufragios competitivos en el país. Sin embargo las votaciones siguientes ya no tuvieron las característica de los comicios municipales de 2008 en el sentido de que en las siguientes (las de 2010, 2011, 2014) el gobierno ya no necesitó implementar prácticas fraudulentas durante el mismo día en que se celebran elecciones, sino que la administración del Estado orquestó de forma sistemática un plan en el que, gracias a la colaboración del Poder Judicial, el control del CSE y la libre disposición de recursos públicos, la oposición -que tradicionalmente ha tenido dificultades para establecer consensos- fue quedando disminuida y sin capacidad de competir. ${ }^{8}$

Pero más allá del control de la administración electoral, desde la reforma electoral de mayo de 2012, es preciso señalar que también se otorgó al CSE la capacidad de revisar de forma continua el padrón electoral, dándole la potestad de eliminar a aquellos ciudadanos que no hayan votado nunca desde 2006 con el fin de purgar ausentes y fallecidos, pero con la posibilidad de sesgar el padrón expulsando desencantados, apáticos y opositores que no han querido participar en elecciones autoritarias.

A raíz de lo expuesto, todo indica que en Nicaragua se pasó de elecciones competitivas (1990-2006) a "elecciones autoritarias contestadas" en 2008, y de estas a "elecciones hegemónicas" desde 2011. Las elecciones de 2011, en las que se elegía Presidente, la Asamblea Nacional y del Parlamento Centroamericano, se llevaron a cabo sin la existencia

8 Acerca de la capacidad del régimen de "dividir a la oposición" es preciso anotar que como al CSE le corresponde vigilar y resolver de los conflictos intra y extrapartidarios, en más de una ocasión los magistrados han intervenido en las peleas intrapartidarias de la oposición debilitando y fraccionándola. 
de un padrón electoral depurado ${ }^{9}$ y sin haber entregado cédulas o documentos supletorios a doscientos mil ciudadanos y sin mostrar, posteriormente, los resultados electorales definitivos. Además no hubo representación de partidos opositores en la composición de las mesas electorales y la gran mayoría de los fiscales eran sandinistas (Pérez Baltodano, 2010; 2012). A pesar de la prohibición expresa de "reelección inmediata" que contenía la Constitución, Daniel Ortega concurrió otra vez como candidato gracias a la misma argucia legal que permitió a Óscar Arias presentarse por segunda vez en Costa Rica: por medio del fallo de un recurso de amparo (Treminio Sánchez, 2015).

En las elecciones para la presidencia de 2011 concurrieron, además de Ortega, otro viejo conocido: Arnoldo Alemán por el PLC. Pero la oposición al sandinismo estuvo dividida entre el PLC y el PLI-UNE, que presentó a Fabio Gadea, un veterano locutor de radio. ${ }^{10}$ Los dos candidatos restantes, con un perfil menor, se percibieron como satélites del FSLN. Según los resultados oficiales Ortega obtuvo el 62,5\% del sufragio y el FSLN 63 diputados, frente al 31\% de Gadea y 31 diputados de la coalición PLI-UNE, y el 5,9\% de Alemán y 2 diputados del PLC. Los dos candidatos restantes no sumaron el 0,6\% del sufragio y no obtuvieron ningún escaño. Según los informes de las comisiones de observación de la OEA y de la UE los comicios estuvieron plagados de irregularidades; opinión con la que coincidieron también las comisiones de observación nacionales Ética y Transparencia, Instituto para el Desarrollo y la Democracia y el Centro Nicaragüense de Derechos Humanos (McConell, 2009).

De todas formas las elecciones de 2011 fueron mucho menos contestadas que las de 2008, a pesar de que el candidato Fabio Gadea dijera que no reconocía los resultados. Según la opinión de los mismos nicaragüenses, esta vez era creíble que el FSLN (a diferencia de los comicios de 2008) hubiera ganado las elecciones (Pérez Baltodano, 2012). La victoria sandinista fue celebrada masivamente por parte de sus seguidores, y la derrota de la oposición se vivió con la resignación silenciosa de quienes nunca creyeron en la posibilidad de enfrentarse con éxito a la maquinaria desplegada a lo largo de un mandato por el FSLN.

Posteriormente, las elecciones municipales del 4 de noviembre de 2012 se planearon por parte del gobierno de Ortega como un paso más hacia el control total del poder del Estado y, sobre todo, una demostración de hegemonía del FSLN. En estas elecciones la oposición liberal (fragmentada entre el PLC y el PLI) se presentó más dividida que en las anteriores. La jornada electoral transcurrió con normalidad dentro de la "anormalidad" de unas elecciones no competitivas donde el FSLN ganó 134 de los 153 municipios del país, controlando todas capitales departamentales menos la de la RAAN (Bilwi) en

9 Además, también es preciso señalar que el padrón electoral con que se realizaron las elecciones era abultado, debido a la presencia de ciudadanos fallecidos, migrantes o con problemas en los datos de ubicación. A la vez que tampoco se ha registrado el crecimiento vegetativo real en el mismo padrón.

10 Fabio Gadea lideró una coalición de liberales (encuadrados en el PLI), conservadores y exsandinistas con las siglas Unidad Nacional para la Esperanza (UNE). 
manos de Yatama. ${ }^{11}$ La participación, según el CSE, fue del 66\%, la más baja de todas las convocatorias electorales desde 1984, y 12 puntos menos que en las anteriores elecciones locales de 2008, donde muchos electores tenían fe en la victoria de la oposición en la capital y en otros núcleos urbanos. En esta dirección, según diversos analistas, el abstencionismo fue un resultado buscado, calculado y logrado desde arriba.

Llegados a este punto parece claro que es difícil que haya sorpresas en las elecciones de 2016. Después de las reformas de la Constitución de 2014, en las que -como se verá en el epígrafe siguiente- se establece la posibilidad de reelección indefinida, nadie duda que Daniel Ortega vuelva a ser candidato y que renueve su cargo de Presidente de la República, y que el FSLN obtenga una amplia mayoría en la Asamblea Nacional. Así las cosas, la realidad electoral debe analizarse a partir de la literatura que trata acerca de elecciones autoritarias, pues como se expone el Equipo Envío (2016), Nicaragua es el único país latinoamericano en que ha visto derrumbarse la credibilidad en la vía electoral como mecanismo cívico para cambiar gobierno.

Con esta pretensión es necesario dar cuenta, parafraseando a Schedler (2004), de cuál es el "menú de la manipulación" que se aplica en Nicaragua en cada una de las siete dimensiones de la elección que son el objeto de la elección, el rango de alternativas, la formación de preferencias, los sujetos de la elección, la expresión de preferencias, la agregación de preferencias y las consecuencias de la elección.

En cuanto al objeto de la elección, es preciso señalar que en Nicaragua no hay dominios ni posiciones reservadas (como sí ocurrió en Brasil durante el régimen autoritario hasta 1985), ya que todos los cargos son electos. Respecto del rango de alternativas (es decir, la libertad de oferta) sí que, desde el año 2000, el CSE y el gobierno han tenido capacidad de moldear la libertad de oferta partidaria de la oposición restringiendo su acceso a la arena electoral, como ocurrió en las elecciones municipales de 2001 al descartar a un candidato a la alcaldía de Managua por medio de rediseñar arbitrariamente el distrito del municipio, y como ha sucedido desde 2006 eliminando la personería jurídica de partidos (como el MRS) o interviniendo en pleitos judiciales intrapartidarios con el fin de desorganizar y fragmentar la disidencia. En este sentido puede afirmarse que el régimen es capaz de maquinar el fracaso de los partidos de la oposición, sacando ventaja de conflictos internos con el fin de dividir y marginar grupos, desorganizar la disidencia, asegurando así la exclusión de competidores, a la par que las exigencias para crear y consolidar un partido son extremadamente exigentes.

Respecto de la formación de preferencias (la libertad de demanda), es posible señalar que existe inequidad en el acceso a los medios de comunicación y al dinero para financiar campañas. Si bien no existe un escenario de inequidad radical debido a la existencia de medios independientes del gobierno como son La Prensa, Canal 12, Radio Corporación,

11 Uno de los pocos análisis publicados relativos a las elecciones es el realizado por la Revista Envío http:/ / www. envio.org.ni/articulo/4611 Las dos organizaciones nicaragüenses más relevantes de control y vigilancia electoral IPADE y Ética y Transparencia no elaboraron informes públicos sobre las elecciones, si bien se manifestaron en contra del desarrollo de los comicios, véase la opinión del director de Ética y Transparencia en El Nuevo Diario http:/ / www.elnuevodiario.com.ni/politica/264399-proceso-electoral-carece-de-credibilidad-dice-etica-transparencia. 
y el semanario Confidencial; sí cabe señalar que la familia Ortega-Murillo y allegados es propietaria de siete estaciones de radio y de tres televisoras (Canal 4, 8, 13), además de controlar Canal 2.12 A la vez existe el control público de Canal 6 y Radio Nicaragua, además del control por parte del FSLN de Radio Sandino y La Primerísima. Aunado a ello el empresario mexicano Ángel González, amigo de Ortega, es propietario de 11 canales de televisión y 12 radios. Además, en cuanto a la restricción de las libertades políticas y civiles puede afirmarse que hay una mezcla vacilante de libertades y controles, sobre todo respecto de las ONG y a la sociedad civil organizada no afín al gobierno (Close, 2016). A ello es significativo añadir la dificultad de la oposición de manifestarse en las calles para protestar -como sucedió después de las elecciones municipales de 2008debido a la movilización gubernamental de grupos de choque.

Concerniente a los sujetos de la elección (la inclusión), si bien no hay restricciones formales al sufragio, el CSE controla el proceso de cedulación y, desde mayo de 2012, de actualización y depuración del patrón electoral, hecho que puede suponer la alteración de la composición del censo. Respecto de la expresión de preferencias, es más complejo emitir un juicio, pues en caso de existir coacción o corrupción es difícil obtener evidencias. Si bien hay quien señala que existe un cierto control clientelista mediante las redes que implementan las políticas de transferencia condicionada (con los CPC y los Gabinetes de Familia), no es posible establecer juicios. Otra cuestión es el de la agregación de preferencias, donde a pesar de que no hay sesgos institucionales en la elección de diputados (con un sistema electoral proporcional perfectamente homologable a otros sistemas democráticos sin casi malapportionment), sí puede afirmarse que ha habido prácticas de disminución de votos no favorables en algunos comicios, como aconteció en los municipales de 2008 en Managua y León, y en los municipales de 2012 en algunas localidades del interior del país. Según denunció la oposición, en ambas elecciones hubo mal conteo de votos, falsificación de actas, credenciales, quema de urnas y, a raíz de todo ello, impugnaciones que nunca fueron atendidas. ${ }^{13}$ Finalmente, es preciso exponer el tema de la decisividad de la elección, es decir, el de la posibilidad de que las elecciones no tengan consecuencias y, con ello, evitar que los funcionarios elegidos ejerzan sus facultades. Este caso se ha dado en Nicaragua con los diputados Xochilt Ocampo y Agustín Jarquín, que fueron despojados de sus escaños (del FSLN), el primero por abstenerse de votar la Ley de concesión de canal interoceánico introducida por el Presidente de la República y el segundo por anunciar la ruptura de su alianza partidaria; a la par que han habido diversas oleadas de destitución de alcaldes por decisión del Presidente, hecho que supone un acto de tutela de las autoridades electas por parte del Ejecutivo Nacional.

Con todo, a pesar de la revisión realizada al "menú de la manipulación" respecto de las siete dimensiones de la elección, es preciso señalar que los recursos de la imaginación autoritaria no son lógicos, sino empíricos. Como señalan Greene, Slater y Schedler

12 Para mayor información véase: “Who Owns the Media in Nicaragua?" Observacom (September 2014). http:// observacom.org/who-owns-the-media-in-nicaragua; y Josué Bravo, "Familia Ortega monopoliza medios de comunicación en Nicaragua", Diario Las Americas (febrero 24, 2015). http://www.diariolasamericas. com/4849_centroamerica/2965310_familia-ortega-monopoliza-medios-de-comunicacion-en-nicaragua.html.

13 Sobre las elecciones municipales de 2008 véase el informe realizado por el Equipo Nitlapán-Envío (2008). 
(2015), el fin de los gobernantes autoritarios es seleccionar ciertas tácticas que les ayuden a extraer el núcleo democrático a las contiendas electorales $\mathrm{y}$, en el caso de los operadores de Ortega, parece que lo han conseguido. No hay duda que desde el 2007 la administración de Ortega ha conseguido elaborar una secuencia de prácticas que violan las normas democráticas de manera tan severa y sistemática que obligan a clasificar elecciones formalmente competitivas que se celebran en Nicaragua desde el 2008 como autoritarias.

Este tipo de práctica, la existencia de elecciones multipartidistas no competitivas, hace que la lucha de la oposición cambie su lógica, ya que muchas veces no se trata solo de competir por votos con el fin de derrotar al gobierno en las urnas, sino también de presionar a otras instancias nacionales e internacionales para lograr reformas institucionales para que los votos cuenten. Con ello los partidos de la oposición se ven inmersos en un ambiente estratégico mucho más complicado del que acontece en un sistema democrático, ya que se ven obligados a hacer -como dice Schedler (2013) - "movimientos de ajedrez hacia atrás y hacia delante", sin saber si con ello pueden provocar una progresión hacia la democracia o un endurecimiento autoritario del régimen. Ciertamente, en los regímenes autoritario-electorales los actores compiten simultáneamente por votos y reglas básicas bajo las que se da la competencia electoral, y se establece un juego a dos niveles donde la oposición tiene razones para coordinar esfuerzos contra el gobierno cuando las elecciones despiertan el interés de la comunidad internacional; a la vez que los actores del régimen tratan de socavar la oposición y de organizar y contener el conflicto.

En este marco el despliegue de la represión y el fraude se llevan a cabo en contextos de elecciones más competitivas, como ocurrió en 2008, cuando el gobierno de Ortega no controlaba el poder legislativo y tenía una posición más vulnerable frente a la oposición, y tuvo que pagar ciertos costos de legitimidad debido a la obvia manipulación electoral en algunas localidades (Martí i Puig, 2013a). Sin embargo, posteriormente se ha utilizado más el recurso a la censura y la exclusión, que es más propio de regímenes hegemónicos que ya cuentan con posiciones supermayoritarias, con capacidad de anticipar y de despojar la incertidumbre inherente a la celebración de elecciones democráticas. ${ }^{14}$

\section{CONTROL DEL PODER: REFORMA CONSTITUCIONAL Y LEALTADES POLÍTICAS}

La evolución constitucional nicaragüense de las últimas tres décadas ha estado marcada por una tensión entre el encumbramiento del poder presidencial y su contención. Cuando se redactó la Constitución de 1987,15 en el marco de un proceso revolucionario liderado por el FSLN, se consagró un régimen presidencial reforzado con un jefe de Estado con amplias potestades normativas y que se alzaba como elemento central de todo el sistema

Tal como señala Schedler (2013: 198), la utilización de censura y exclusión de manera estratégica y preventiva en las fases tempranas del ciclo electoral suponen una menor necesidad de depender del fraude y de la represión.

15 Es la Constitución actualmente vigente a pesar de las reformas. 
jurídico-político. Posteriormente, en 1995, a raíz del escenario político posterior a las elecciones de 1990 y bajo la presidenta Violeta Barrios de Chamorro, se llevaron a cabo varias reformas constitucionales que tuvieron como fin disminuir algunas atribuciones presidenciales (entre ellas se limitó la reelección presidencial que había quedado sin tipificar en 1987) y fortalecer la posición de la Asamblea Nacional. Unos años más tarde, en 2005, con la administración del presidente Enrique Bolaños, volvieron a llevarse a cabo nuevas reformas que volvieron a limitar las potestades del Presidente configurando un régimen presidencial parlamentarizado (Álvarez y Vintró, 2009).

Sin embargo con el retorno a la presidencia de Daniel Ortega en 2007 se dio inicio al proceso inverso: la devolución de potestades al Presidente de la República para volver a convertirlo en el eje central del poder alrededor del cual giran las demás piezas del sistema. Los objetivos de las reformas constitucionales del 2014 fueron garantizar normativamente el reforzamiento de la figura presidencial -a la par que se cambiaban las reglas relativas a su elección- e introducir mecanismos de democracia participativa (Álvarez y Vintró, 2014). Además, es admisible señalar que a diferencia de otros procesos constituyentes en América Latina, este se llevó a cabo mediante la enmienda parcial de un altísimo porcentaje de artículos, y con ello se evadió la convocatoria a una constituyente que quizás hubiera supuesto un mayor espacio para que grupos sociales y ciudadanos se pronunciaran sobre la misma.

Respecto del fortalecimiento de la figura del Presidente es fundamental señalar los siguientes cambios. El primero fue volver a otorgarle la potestad de dictar decretos ejecutivos de aplicación general en materia administrativa. Esta atribución, que existía en la Constitución de 1987 y que fue suprimida en la reforma de 1995, se recuperó en $2014 .{ }^{16}$ Con ello, el Presidente de la República se convirtió a sí mismo en un órgano prácticamente colegislador, junto con el Parlamento. El segundo fue suprimir la comparecencia del Presidente ante la Asamblea Nacional para presentar su informe anual personalmente o por medio del vicepresidente de la República. Y, el tercero y último, fue darle la capacidad de ratificar los nombramientos presidenciales de altos cargos con mayoría simple de la Asamblea Nacional. ${ }^{17}$ A estos elementos de reforzamiento presidencial debe sumársele, a la vez, el debilitamiento de la Asamblea Nacional al atribuir la titularidad del escaño parlamentario a los partidos y no a los representantes elegidos.

En cuanto a la elección presidencial, en las reformas de 2014 se eliminaron las restricciones a la reelección indefinida y se estableció un sistema electoral de mayoría simple, convirtiéndose Nicaragua en el segundo país de la región en adoptar este tipo de reelección después de Venezuela en 2009 (Treminio Sánchez, 2015). Con ello se supone que se ha abierto la posibilidad de perpetuar a la figura de Daniel Ortega en la Presidencia de la República con cobertura constitucional y no mediante la muy discutible solución

16 La única excepción a esta potestad es la referente a la regulación en materia fiscal que sigue reservada a la ley formal de la Asamblea Nacional.

17 Con ello se suprime el redactado de reforma constitucional del año 2005 en el que se exigían la ratificación de los nombramientos por parte de la Asamblea Nacional mediante una mayoría cualificada del $60 \%$ de los diputados, si bien desde 2007 Daniel Ortega solo lo cumplió parcialmente. 
(mediante sentencias de los de la Corte Suprema de Justicia) con la que en 2011 Ortega se saltó la prohibición de la reelección presidencial consecutiva establecida en el texto constitucional de 1995.

Respecto de la introducción de elementos de democracia directa, la reforma de 2014 expone en el artículo 2 la previsión y despliegue de mecanismos de democracia participativa en donde el pueblo puede ejercer el "poder soberano". Entre estos mecanismos están el referéndum, el plebiscito, los presupuestos participativos, las iniciativas ciudadanas, los consejos territoriales, las asambleas territoriales y comunales de los pueblos originarios y afrodescendientes y los consejos sectoriales. En consistencia con este nuevo redactado, el artículo 6 señala el papel protagónico de las ciudadanas y ciudadanos y la familia en la toma de decisiones, planificación y gestión de los asuntos públicos del Estado; y el artículo 50 garantiza la participación de la persona, la familia y la comunidad en la formulación, ejecución, evaluación, control y seguimiento de las políticas públicas y sociales y de los servicios públicos. Como exponen Álvarez y Vintró (2014), este conjunto de herramientas se "constitucionalizaron" en bloque, pues el referéndum y el plebiscito ya se encontraban en la anterior regulación constitucional del artículo 2,18 y la iniciativa ciudadana también se encontraba regulada aunque concebida como un mecanismo de iniciativa legislativa. El resto de mecanismos, sin embargo, sí se introdujeron en el artículo 2, ya que antes se habían desarrollado en la legislación ordinaria con los llamados consejos y gabinetes del poder ciudadano regulados en el Decreto 112-2007. Sin embargo, entre las herramientas de participación que podrían haberse introducido no figuran algunos importantes mecanismos de control como son la revocación por votación ciudadana de titulares de determinadas instituciones, que sí se prevé en muchas constituciones latinoamericanas.

Pero más allá de la descripción de las reformas, es importante exponer que las dos primeras (otorgamiento de mayores potestades y cambio de reglas en la elección del Presidente de la República) suponen directamente el fortalecimiento de la figura de Daniel Ortega, y la tercera un mayor control del aparato del FSLN sobre las instituciones públicas. La posibilidad de reelección indefinida por mayoría simple y la capacidad de colegislar del ejecutivo suponen una concentración del poder propia de los tiempos de la revolución, sin revolución. A la vez, a las reformas ya expuestas debe sumárseles una nueva relación de los cuerpos armados con la presidencia de la república.

Respecto de la naturaleza de los dos cuerpos armados nicaragüenses es fundamental señalar que estos tuvieron su origen en la Revolución Popular Sandinista. Posteriormente, en los años noventa, ambos tuvieron un proceso de institucionalización con la promulgación del Código de Organización Jurisdiccional y Previsión Social Militar en 1994 (Ley 181) y con la reforma constitucional de 1995. A raíz de estas reformas el Ejército Popular Sandinista pasó a ser el Ejército de Nicaragua y la Policía Sandinista a la Policía Nacional, convirtiéndose en instituciones sin estigma partidario. En este proceso fue muy relevante

18 El referéndum y el plebiscito fueron incorporados en el artículo 2 de la Constitución mediante Ley de reforma parcial a la Constitución Política, publicada en La Gaceta, Diario Oficial, 4 de julio de 1995, Nº 124. 
también la creación del Ministerio de Defensa y el Ministerio de Gobernación, que supuso una nueva fase de relaciones cívico-militares donde los jefes de los cuerpos armados dependían de sus respectivos ministros y no directamente del Presidente de la República. Este proceso, sin embargo, se interrumpió en 2007 al llegar nuevamente Ortega a la presidencia, ya que se volvió a establecer un modelo de relación directa entre el Presidente y las instituciones armadas. Este proceso se inició de manera informal y se legalizó con la reforma constitucional de 2014 y con la reforma del Código Militar (Ley 855) y la nueva Ley de la Policía Nacional (Ley 872). Además, con el nuevo Código Militar también se permite a los miembros de las Fuerzas Armadas ocupar cargos en el ámbito del poder ejecutivo si lo requieran "razones de seguridad nacional" o cuando "el interés supremo de la nación lo demande". Este hecho abre la puerta a la presencia de militares en asuntos civiles; situación compleja si se tiene en cuenta que las tareas de seguridad nacional e inteligencia también se han atribuido al Ejército (IEEPP, 2015) y que la nueva ley de seguridad -llamada Ley Seguridad Soberana- restringe libertades de reunión y expresión cuando se interpretan que van en contra del interés nacional.

En cuanto a la tercera reforma, la de constitucionalizar formas de participación directa, es importante señalar que si bien esta podría suponer un importante activo a la democratización del país, también puede significar un mayor control partidista de las instituciones y de las políticas públicas ${ }^{19}$ debido a que tanto los CPC como los Gabinetes de Familia han mantenido una estrecha vinculación con el FSLN desde su creación (Close, 2016; Stuart, 2009). A la vez, el Gabinete Nacional del Poder Ciudadano está presidido por el Presidente de la República y coordinado por su esposa Rosario Murillo, quien también es la coordinadora del Consejo de Comunicación y Ciudadanía para el Desarrollo y el Bienestar Social. ${ }^{20}$ En este sentido otorgar mayor peso a los CPC supone agregar mayor control partidario y restar autonomía y poder real a las instituciones representativas.

Pero más allá de lo expuesto, el control omnímodo que Ortega ha ido estableciendo en el andamiaje institucional se ha combinado con políticas de promoción de las actividades de agroexportación tradicionales como el cultivo del café, carne de vacuno, azúcar, tabaco o maní. Este crecimiento, además, ha sido muy exitoso y se ha realizado sobre la misma base macroeconómica neoliberal de los gobiernos anteriores. La estrategia ha sido mantener e impulsar la apertura de la economía nicaragüense al comercio exterior, y la obtención de préstamos favorables para quienes han controlado el proceso de procesamiento del producto, su comercio y su exportación (Martí i Puig y Baumeister, en prensa).

Esta lógica neoliberal iniciada en la década de los noventa se ha mantenido con la administración Ortega e incluso se ha incrementado, como puede verse en las Tablas 1 y 2 donde se muestra el incremento de las exportaciones.

19 Según el decreto 112-2007 las funciones de los CPC son apoyar los planes y las políticas del Presidente de la República encaminadas a desarrollar determinados objetivos (art. 1).

20 La responsabilidad de Rosario Murillo en este puesto es la de coordinar el "gabinete social" y todos los programas de sociales implementados desde las instituciones públicas, así como dirigir el Sistema de Bienestar Social. 
Tabla 1. Exportaciones FOB: volumen físico de los principales productos (1998-2014)

\begin{tabular}{lcccc}
\hline $\begin{array}{l}\text { Años } \\
\text { (miles) }\end{array}$ & $\begin{array}{c}\text { Café } \\
\text { Qq. }\end{array}$ & $\begin{array}{c}\text { Carne } \\
\text { Kg }\end{array}$ & $\begin{array}{c}\text { Azúcar } \\
\text { Qq. }\end{array}$ & $\begin{array}{c}\text { Frijol } \\
\text { Kg }\end{array}$ \\
\hline 1998 & 948 & 22.856 & 2.661 & 13.506 \\
2002 & 1.533 & 33.341 & 4.340 & 32.253 \\
2006 & 1.921 & 49.622 & 4.440 & 54.272 \\
2014 & 2.462 & 96.045 & 9.436 & 64.792 \\
\hline
\end{tabular}

Fuente: Exportaciones según estadísticas del Banco Central de Nicaragua y del CETREX en Martí i Puig y Baumeister, en prensa.

Tabla 2. Exportaciones agrícolas principales (en millones de dólares) y relación con el Producto Bruto Agropecuario (2000-2014)

\begin{tabular}{lrrcc}
\hline & 2000 & 2006 & 2014 & $\begin{array}{c}\text { Cambio } \\
\text { porcentual entre } \\
2014 \text { y 2006 }\end{array}$ \\
\hline Azúcar & 36,4 & 55,5 & 194,3 & 250 \\
Café & 165,4 & 210,3 & 394,5 & 88 \\
Carne vacuno & 25,7 & 151,3 & 456,4 & 202 \\
Maní & 29,6 & 44,6 & 116,6 & 161 \\
Lácteos & 25,0 & 62,5 & 191,4 & 206 \\
Frijoles & 7,5 & 37,1 & 82,8 & 123 \\
Subtotal & 289,6 & 561,3 & 1436 & 156 \\
\% exp. agr./PIBA & 39,8 & 52,3 & 65,8 & \\
\hline
\end{tabular}

Fuente: Exportaciones según CETREX y el PIBA según BCN Martí i Puig y Baumeister, en prensa.

En este sentido se puede afirmar que el modelo privado de producción y comercialización iniciado en 1990, para el mercado nacional y el exterior, no solo ha continuado con la administración sandinista, sino que se ha intensificado con el acceso privilegiado al mercado de Venezuela, con la activa participación de empresas público-privadas gestionadas por empresarios vinculados a la administración sandinista, bajo la protección empresarial de ALBANISA. ${ }^{21}$ del 49\%, perteneciendo a Petróleos de Venezuela (PDVSA) el restante 51\%. Fue creada en 2007, como consecuencia del ingreso de Nicaragua a la Alianza Bolivariana para los Pueblos de Nuestra América (ALBA). Desde su creación, ALBANISA ha diversificado rápidamente sus actividades, y a su propósito inicial de distribución del petróleo llegado desde Venezuela, ha agregado, mediante la creación de distintas empresas, operaciones e intereses en sectores como maquinaria de construcción, generación de energía, servicios de seguridad, hoteles, ganadería, transporte, préstamos, manejo portuario y distribución de gas. Para más información véase: http://www.centralamericadata.com/es/article/home/Alba_de_Nicaragua_Sociedad_Anonima. 
Con este modelo productivo neoliberal los gobiernos de Ortega han mantenido y ampliado la cooperación con organismos multilaterales como el FMI, el Banco Mundial, Banco Interamericano de Desarrollo (BID) y Banco Centroamericano de Integración Económica (BCIE), y han incrementado la presencia de la inversión extranjera directa en varios rubros, fundamentalmente producción primaria en armonía con las élites empresariales tradicionales del Consejo Superior de la Empresa Privada (COSEP), a las que se han sumado los grupos económicos de capital extranjero y otros vinculados directamente al FSLN (Spalding, 2016).

Ha sido en este marco en el que el gobierno sandinista ha contribuido también en la mejora de las condiciones de las personas con menos recursos en las zonas rurales y urbanas con diversas políticas sociales focalizadas en la lucha contra la pobreza, muchas veces se han implementado mediante los CPC (Spalding, 2009). Es razonable suponer que el éxito de Nicaragua en la lucha contra la pobreza ha contribuido tanto a su crecimiento económico general como al mantenimiento de paz social entre los sectores populares, las élites tradicionales y la administración de Daniel Ortega. ${ }^{22}$

La cuestión, sin embargo, estriba en saber hasta cuándo va a durar la capacidad del gobierno y el FSLN para mantener el control social, económico y político del país. Una respuesta sensata pasa por preguntar si la élite económica continuará percibiendo que la presidencia de Ortega (que impulsa una política que les beneficia y controla los sindicatos) es más un activo que un pasivo para sus intereses, ${ }^{23}$ y de si el FSLN podrá continuar conteniendo las movilizaciones sociales y a la par de neutralizar la oposición política. Esto es importante, porque Nicaragua en 2016 sigue siendo un país extremadamente vulnerable, con un IDH del 0,614 (que le sitúa en el lugar 126 de los 187 países evaluados, solo por encima de Guatemala, Honduras y Haití en la región ${ }^{24}$ ), con graves déficits educativos, con el $42 \%$ de los 6 millones de habitantes viviendo en zonas rurales (PNUD, 2015).

Hasta la fecha, Ortega y su partido han sido capaces de conjugar crecimiento económico, tener el apoyo de las élites tradicionales, asegurar paz social y la disminución de la pobreza. Sin embargo, en el futuro se presentan algunas señales que hacen prever un futuro incierto. A nivel económico la incertidumbre se relaciona con el fin del ciclo económico alcista a raíz del descenso de las exportaciones nicaragüenses a los Estados Unidos y a Venezuela y de la bajada de los precios de los productos agropecuarios (FUNIDES, 2015). A nivel social el fin del "consenso sandinista" se manifiesta por la creciente necesidad de utilizar la represión por parte del Estado, como ha acontecido

22 Considerando que son pobres aquellos que viven con US\$ 2,50 al día, en 2001 el 69,4\% de los nicaragüenses eran pobres, mientras que en 2012 lo eran el 42,7\%; y considerando que viven en extrema pobreza quienes solo disponen de US\$ 1,25 al día, en 2002 lo estaban el 42,5\% de la población mientras que en 2013 el 7,6\% (FIDEG 2012).

23 La primera batalla que han librado es la del control de internet, que se inició en 2013 y aún no ha concluido, y donde el gobierno quiere poner bajo control militar internet y los empresarios se resisten. Vásquez y Mabel Calero, “Gobierno insiste en papel de ciberpolicía", La Prensa (May Vladimir 10, 2015). Véase: http://www. laprensa.com.ni/2015/05/10/nacionales/1829551-gobierno-insiste-en-papel-de-ciberpolicia

24 Según el Informe de Desarrollo Humano de la PNUD de 2015. Guatemala se encuentra en el puesto 128, Honduras en el 131 y Haití en 163. 
en las protestas frente a las concesiones mineras en algunas comunidades, ${ }^{25} \mathrm{o}$ frente a la oposición a la construcción del Canal Interoceánico concesionada por el gobierno a la empresa China HKND. En este sentido es ilustrativo que ante el número creciente de protestas durante el 2015, Bayardo Arce -asesor económico de Ortega y uno de los nueve comandantes de la revolución- declaró a fines de 2015 que las "protestas son para desestabilizar al gobierno" y que para ello se aprobaría una legislación (Ley de Seguridad Soberana) para neutralizar las actividades sediciosas.

Finalmente, a nivel político, si bien todo indica que en las próximas elecciones de 2016 no habrá incertidumbre y que el FSLN de Daniel Ortega y Rosario Murillo va a arrasar nuevamente, también se abren algunas interrogantes acerca de la estabilidad política del régimen debido a tres escenarios futuros. El primero es la unión de la oposición, que si bien actualmente está dividida en dos facciones liberales, ${ }^{26}$ puede generar un proceso de convergencia al demandar observación internacional y condiciones "limpias y neutrales" para la elección de 2016. El segundo es la irrupción de inestabilidad social y política en la Costa Atlántica, espacio donde el FSLN ha visto erosionado su apoyo tras su ruptura con la formación costeña, Yatama, liderada por el antiguo opositor y luego aliado sandinista, Brooklyn Rivera. ${ }^{27} \mathrm{Y}$ el tercero es el incremento del aislamiento internacional del gobierno con la crisis económica que impera en Venezuela y la derrota del oficialismo en las últimas elecciones legislativas; junto con la más que discreta presencia de la delegación nicaragüense en la Cumbre Américas en Panamá; la expulsión y abandono en 2015 de la representante residente del PNUD en Nicaragua; y las distantes relaciones que mantiene con los países vecinos..$^{28}$ En esta misma dirección, es preciso interpretar algunas señales de aislamiento internacional como el distanciamiento de Washington, plasmado en las declaraciones de la nueva embajadora norteamericana, Laura Dogu, quien dijo que "el gobierno nicaragüense debía respetar la voluntad del pueblo". De todas formas, hasta la fecha, parece que Daniel Ortega no percibe que el fin de su mandato sea inminente, como mínimo así lo planteó en una reunión con varios obispos nicaragüenses en la que

Como ocurrió en la mina El Limón el 17 de octubre de 2015 cuando 400 antimotines disolvieron a quienes se oponían a su explotación por parte de la empresa minera canadiense R2GOLD.

A inicios de 2016 se vislumbran dos candidaturas liberales para las elecciones. Por un lado, una abanderada por el PLC y liderada por el candidato conservador, Noel Vidaurre. Por el otro está una aglutinada alrededor del PLI en la que se han sumado sandinistas provenientes del MRS.

27 Desde la última década, pero sobre todo en el último año, ha incremento notablemente la conflictividad en la Costa Atlántica. Las razones de ello son al agotamiento de la frontera agrícola en el país, hecho que ha llevado al enfrentamiento de colonos con miembros de comunidades indígenas; el asentamiento de redes de negocios ilegales; y la presión sobre el territorio por recursos naturales y yacimientos. A resultas de ello el crimen contra la población indígena se ha elevado exponencialmente en la Región Autónoma del Atlántico Norte (RAAN). A raíz de esta situación se han cursado diversas denuncias a la Comisión Interamericana de Derechos Humanos, la última fue presentada en 2015 por la ONG Comisión de Estudios sobre Justicia y Derechos Humamos de la Costa Atlántica Norte (CEJDHCAN) denunciando la desaparición de 24 indígenas muertos.

28 Dos muestras de la tensa relación que Nicaragua mantiene con Costa Rica son, por un lado, la crisis de los refugiados cubanos que se inició en septiembre de 2015 y, por otro lado, los conflictos territoriales en el río San Juan a raíz de los planes de construcción del Canal Interoceánico. Por otro lado, es esencial señalar las buenas relaciones que mantiene el gobierno de Ortega con socios lejanos, como es Rusia, a quien le ha cedido la "utilización de espacio ultraterrestre". 
les dijo "que tuvieran paciencia, porque el Frente Sandinista seguiría gobernando por décadas" (Equipo Envío, 2015).

\section{IV. ¿QUÉ TIPO DE RÉGIMEN TIENE HOY NICARAGUA?}

¿Qué tipo de sistema político ha instaurado Daniel Ortega desde su llegada a la Presidencia de la República en 2007? Para responder de forma cabal esta pregunta es necesario tener en cuenta que desde la derrota electoral de Ortega en 1990 este empezó la tarea de controlar el partido y, desde la oposición, las instituciones. ${ }^{29}$ Cuando ganó las elecciones presidenciales en 2006 Ortega (junto con su mujer) ya tenía el control total del partido, dominaba la mayor parte del sistema judicial y tenía una gran ascendencia en el Ejército y la Policía. Sin embargo, ha sido a partir de 2007, con la Presidencia de la República en sus manos, cuando se ha instaurado un sistema político donde el poder se estructura y se ejerce jerárquicamente con un carácter extremadamente personalista y sin ningún interés de rendir cuentas ni explicaciones. ${ }^{30}$ Un ejemplo claro de esta realidad es que la residencia familiar de Daniel Ortega y Rosario Murillo es a la vez la oficina central del FSLN y la Casa Presidencial.

Con todo, el régimen instaurado no es un sistema autoritario al uso, pues en Nicaragua hay espacio para la acción política independiente, aunque la capacidad para desafiar al gobierno es muy restringida y, cuando se percibe efectiva, el régimen generalmente actúa de forma eficaz contra sus rivales. Tampoco se trata de un sistema de partido único como el de los Castro en Cuba, ni de un régimen represivo como los que existieron en el Cono Sur durante los años setenta, ni como el de los demás aliados bolivarianos. Como expone Close (2016), el régimen de Ortega se asemeja más a los caudillismos tradicionales de antaño, donde el jefe controlaba la administración del Estado, el Ejército, la Policía, las agencias supuestamente independientes, la maquinaria electoral y los tribunales, como también dominaba y arbitraba negocios. Como en caso de los regímenes descritos, Ortega también tiene un notable control sobre los medios de comunicación y cambia la Constitución a su antojo, pero se diferencia de ellos en dos cuestiones: presta una notable atención al mantenimiento de su clientela electoral y utiliza excepcionalmente la fuerza y la represión (Corrales, 2008). Además, el Presidente goza de niveles relativamente altos de apoyo popular y mantiene una gran red de intereses que permea desde las altas esferas económicas hasta los sectores sociales más desfavorecidos. Por todo ello es difícil de clasificar el sistema político que hoy impera en Nicaragua, si bien, podría calificarse como una actualización del viejo caudillismo latinoamericano por medio del control

29 Este fenómeno - el de la personalización y patrimonialización del FSLN- en manos de la familia Ortega se inició hace más de una década, pero en 2012 llegó a su máxima expresión. Corceniente a ello véase Martí i Puig (2010a, 2010b). Respecto del control familiar del FSLN véase el análisis que aparece en el número 370 de la Revista Envío, http:/ / www.envio.org.ni/articulo/4639. Respecto a cómo Ortega tuvo la capacidad de moldear las instituciones desde la oposición a su favor, véase Close (2012).

30 Desde 2007 Ortega no da conferencias de prensa. También es indicativo que el informe BTI (2016) haya señalado cómo desde 2008 hasta 2016 el Índice de Democracia ha pasado de 6,65 (sobre 10) en 2008 a 5,69 en 2016. 
de los medios de comunicación y del despliegue de políticas sociales focalizadas, con ingredientes de familismo amoral. ${ }^{31}$

La cuestión, sin embargo, radica en que este tipo de sistemas -si bien pueden escaparse de la incertidumbre electoral-perviven con múltiples "incertidumbres institucionales", pues sus autoridades nunca pueden saber con certeza el apoyo que tienen al no existir mecanismos efectivos para pulsar la opinión pública de la sociedad o para saber el apoyo político real con el que cuentan. En esta situación, cuando la oposición empieza a ganar terreno, es imposible saber si el aumento de represión o de la manipulación detendrá o acelerará su declive. En este marco -más allá de la afirmación de Ortega de que "hay FSLN para décadas" (Equipo Envío, 2015)- es admisible preguntarse qué puede ocurrir si la economía se deteriora como ha ocurrido en Venezuela, si se quiebran las alianzas con las élites tradicionales, o si hay una crisis de sucesión.

\section{BIBLIOGRAFÍA}

Álvarez, Gabriel y Vintró, Joan. 2009. “Evolución constitucional y cambios institucionales en Nicaragua (1987-2007)". En: Nicaragua y el FSLN (1979-2009) ¿Qué queda de la revolución?, editado por Salvador Martí i Puig y David W. Close. Barcelona: Edicions Bellaterra, 169-220.

2014. "Nicaragua: claroscuros de la reforma constitucional de 2014". Revista Catalana de Dret Públic, Barcelona. Consultado en: http:/ /blocs.gencat.cat/blocs/AppPHP/eapc-rcdp/2014/03/19/ nicaragua-claroscuros-de-la-reforma-constitucional-de-2014-gabriel-alvarez-y-joan-vintro/\#more-1021.

Banfield, Edward C. 1958. The Moral Basis of a Backward Society. Glencoe, IL: The Free Press.

CINCO. 2016. "Los dilemas de la oposición". Perspectivas 102. Consultado en: http://confidencial.com. ni/quien-quien-la-oposicion/.

Close, David y Deonandan, Kalowaitie (ed). 2004. Undoing Democracy: The Politics of Electoral Caudillismo. New York: Lexington Books.

Close, David; Martí i Puig, Salvador y McConell, Shelley (ed.). 2011. The Sandinistas and Nicaragua Since 1979. New York: Lynne Rienner.

Close, David. 1999. The Chamorro Years. Boulder: Lynne Rienner.

2012. “Las reelecciones de Óscar Arias, Alan García y Daniel Ortega (2006): Tres comebacks políticos excepcionales". Revista Uruguaya de Ciencia Política 21 (2): 55-76.

2016. Nicaragua: Navigating the Politics of Democracy. New York: Lynne Rienner.

Corrales, Javier. 2008. "Latin Americas' Neocaudillism: Ex-Presidents and Newcomers Running for President. and Winning". Latin American Politics and Society 50 (3): 1-35.

Dye, David R. con Jack Spence y George Vickers. 2000. Patchwork Democracy: Nicaraguan Politics Ten Years after the Fall. Washington D.C.: Hempisphere Initiative.

Equipo Envío. 2015. "El proyecto de Ortega en arenas movedizas". Revista Envío 397. Consultado en: http://www.envio.org.ni/articulo/4976.

31 El concepto "familismo amoral" aparece en la obra de Banfield (1958) y se cita en Close (2016) para hablar de Nicaragua. El concepto describe un componente propio de determinadas sociedades (en su caso del sur del mediterráneo, pero extensible a otras geografías) según el cual los individuos velan sobre todo, o solo, por ellos mismos y por sus familias, y cualquier cosa que se haga en beneficio propio o de los parientes próximos es percibido como moralmente positivo y reconocido como tal. En la misma lógica, cualquier cosa que haga para engañar o aprovecharse de las instituciones, del Estado o de cualquier instancia pública, fiscal, legal o administrativa, es una prueba de habilidad y de inteligencia y reconocida como un valor positivo. Acerca de este tema véase la nota de la obra de Banfield en: http:/ / www.nabarralde.com/es/munduan/4475-el-familista-amoral. 
2016. "Boceto pre-electoral". Revista Envío 406. Consultado en: http://www.envio.org.ni/ articulo/5133.

Equipo Nitlapán-Envío. 2008. “Elecciones municipales: una crisis anunciada”. Revista Envío 320. Consultado en: http://www.envio.org.ni/articulo/3890.

FIDEG. 2012. Encuesta de hogares para medir la pobreza en Nicaragua. Managua. Consultado en: http:/ / www. fideg.org/investigaciones-y-publicaciones/107-2013-06-26-00-53-17.

Fundación Bertelsman. 2016. Transformation Index BTI. Consultado en: http://www.bti-project.org/en/home/

FUNIDES. 2015. Coyuntura económica III Trimestre 2015. Funides: Managua. Consultado en: http:/ funides. com/?smd_process_download=1\&download_id=8578.

Greene, Kenneth F.; Slater, Dan; y Schedler, Andreas. 2015. "La política comparada de las elecciones autoritarias. Un debate en torno a The Politics of Uncertainty: Sustaining and Subverting Electoral Authoritarianism de Andreas Schedler". Política y Gobierno 22 (1): 227-246.

IEEPP, Instituto de Estudios Estratégicos y Políticas Públicas. 2015. Novena reforma constitucional. 2014. El cambio de las reglas del juego democrático en Nicaragua. Managua: IEEPP. Consultado en: http:// www.ieepp.org/index.php/presentan-analisis-juridico-de-novena-reforma-constitucional-2014/.

Levitsky, Steven y Lucan A. Way. 2010. Competitive Authoritarianism: Hybrid Regimes After Cold War. NY: CUP. Martí i Puig, Salvador y Close, David W. (ed). 2009. Nicaragua y el FSLN (1979-2009) ¿Qué queda de la revolución? Barcelona: Edicions Bellaterra.

Martí i Puig, Salvador y Baumeister, Eduardo (en prensa). "Nicaragua: From post-revolution Agrarian Reform to a Neo-developmentalism". Journal of Agrarian Change.

Martí i Puig, Salvador. 2008. "El regreso del FSLN al poder: ¿Es posible hablar realineamiento electoral en Nicaragua?". Politica y Gobierno 15 (1): 75-112.

. 2010. "The Adaption of FSLN: Daniel Ortega's Leadership and Democracy in Nicaragua". Latin America Politics and Society 52 (4): 79-106.

. 2013a. "Nicaragua: la consolidación de un régimen híbrido". Revista de Ciencia Política 33 (1): $269-286$

2013b. Nicaragua (1979-1990): La revolución enredada. Edición electrónica en Creative Commons: https://www.academia.edu/1621806/NICARAGUA_1979-1990._LA_REVOLUCIÓN_ ENREDADA.

McConell, Shelley. 2009. "La evolución incierta del sistema electoral nicaragüense". En Nicaragua y el FSLN (1979-2009) ¿Qué queda de la revolución?, editado por Salvador Martí i Puig y David Close. Barcelona: Edicions Bellaterra, 263-309.

.2011. "The Uncertain Evolution of the Electoral System". En The Sandinistas and Nicaragua Since 1979, editado por David Close, Salvador Martí i Puig y Shelley McConell. New York: Lynne Rienner, 121-160.

O’Donnell, Guillermo. 1997. “'Democracia delegativa?”. En Contrapuntos. Ensayos escogidos sobre autoritarismo y democratización. Buenos Aires: Paidós, 287-304.

Pérez-Baltodano, Andrés. 2010. “Nicaragua: se consolida el estado por derecho (y se debilita el estado de derecho)". Revista de Ciencia Política 30: 397-417.

. 2012. "Nicaragua: Democracia electoral sin consenso social". Revista de Ciencia Política 32 (1): 211-228.

PNUD 2015. Informe sobre Desarrollo Humano 2015. Trabajo al servicio del desarrollo humano. NY: PNUD.

Przeworski, Adam. 1986. "Algunos problemas en el estudio de la transición hacia la democracia". En Transiciones desde un régimen autoritario. Vol.3, editado por Guillerom O'Donnell, Philippe Schmitter y Laurence Whitehead. Buenos Aires: Paidós, 79-104.

Schedler, Andreas. 2004. "Elecciones sin democracia. El menú de la manipulación electoral". Estudios Políticos 24: 137-156.

2013. The Politics of Uncertainty: Sustaining and Subverting Electoral Authoritarianism. Oxford: Oxford Universuty Press.

Spalding, Rose. 2009. “Las políticas contra la pobreza en Nicaragua”. En Nicaragua y el FSLN (1979-2009) ¿Qué queda de la revolución?, editado por Salvador Martí i Puig, y David W Close. Barcelona: Edicions Bellaterra, 351-381. 
2014. "Social Movements in Central America". En Handbook on Central American Governance, editado por Diego Sánchez-Ancoehea and Salvador Martí i Puig. NY: Routledge, 265-286.

2016. "Los empresarios y el estado en la Nicaragua post-revolucionaria: el reordenamiento de las élites y la nueva estrategia de colaboración". En Élites en las Américas: Diferentes perspectivas (en prensa) editado por Adriano Codato y Fran Espinoza. Madrid: Editorial Vervuent.

Stuart Almendárez, Roberto (ed.). 2009. "Consejos del Poder Ciudadano y gestión pública en Nicaragua". Managua: CEAP. En: http://www.oas.org/juridico/spanish/mesicic3_nic_consejos.pdf.

Treminio Sánchez, Ilka. 2015. “Las reformas a la reelección presidencial del nuevo siglo en América Central. Tres intentos de reforma y un golpe de estado". Política y Gobierno 22 (1): 147-173.

Salvador Martí i Puig es Doctor en Ciencia Política y profesor titular de Universidad Girona. Su área de especialización es la política comparada, y ha investigado sobre procesos de democratización en América Latina, movimientos sociales, y partidos y sistemas de partidos. Entre sus últimos trabajos destacan la coautoría, con Josep M. Vallès, del libro Ciencia Política. Un Manual (Ariel 2015) y la coedición, junto con Diego Sánchez-Acoechea del Handbook on Central American Governance (Routledge 2014). E-mail: salvador.marti@udg.edu. 